Audiology

Neurotology
Audiol Neurotol 2016;21:54-67

DOI: $10.1159 / 000442513$
Received: January 29, 2015

Accepted after revision: November 17, 2015

Published online: February 18, 2016

\title{
Intracochlear Position of Cochlear Implants Determined Using CT Scanning versus Fitting Levels: Higher Threshold Levels at Basal Turn
}

\author{
Feddo B. van der Beek ${ }^{\mathrm{a}}$ Jeroen J. Briaire ${ }^{\mathrm{b}}$ Kim S. van der Marel ${ }^{\mathrm{b}}$ \\ Berit M. Verbist ${ }^{c}$ Johan H.M. Frijns ${ }^{b}$ \\ ${ }^{a}$ Department of Otolaryngology, Medical Spectrum Twente, Enschede, and Departments of ${ }^{\text {b }}$ Otolaryngology and \\ 'Neuroradiology, Leiden University Medical Center, Leiden, The Netherlands
}

\section{Key Words}

Clinical levels $\cdot$ Cochlear implant $\cdot$ Intrascalar position .

Speech perception $\cdot$ Fitting $\cdot$ Radiology

\begin{abstract}
Objectives: In this study, the effects of the intracochlear position of cochlear implants on the clinical fitting levels were analyzed. Design: A total of 130 adult subjects who used a $\mathrm{Cll} /$ HiRes $90 \mathrm{~K}$ cochlear implant with a HiFocus $1 / 1 \mathrm{~J}$ electrode were included in the study. The insertion angle and the distance to the modiolus of each electrode contact were determined using high-resolution CT scanning. The threshold levels (T-levels) and maximum comfort levels (M-levels) at 1 year of follow-up were determined. The degree of speech perception of the subjects was evaluated during routine clinical follow-up. Results: The depths of insertion of all the electrode contacts were determined. The distance to the modiolus was significantly smaller at the basal and apical cochlear parts compared with that at the middle of the cochlea $(p<0.05)$. The T-levels increased toward the basal end of the cochlea (3.4 dB). Additionally, the M-levels, which were fitted in our clinic using a standard profile, also increased toward the basal end, although with a lower amplitude (1.3 dB). Ac-
\end{abstract}

\begin{tabular}{|c|c|}
\hline KARGER & $\begin{array}{l}\text { (C) } 2016 \text { The Author(s) } \\
\text { Published by S. Karger AG, Basel } \\
1420-3030 / 16 / 0211-0054 \$ 39.50 / 0\end{array}$ \\
\hline www.karger.com/aud & $\begin{array}{l}\text { This article is licensed under the Creative Commons Attribution- } \\
\text { NonCommercial-NoDerivatives } 4.0 \text { International License (CC BY- } \\
\text { NC-ND) (http://www.karger.com/Services/OpenAccessLicense). } \\
\text { Usage and distribution for commercial purposes as well as any dis- } \\
\text { tribution of modified material requires written permission. }\end{array}$ \\
\hline
\end{tabular}

cordingly, the dynamic range decreased toward the basal end $(2.1 \mathrm{~dB})$. No correlation was found between the distance to the modiolus and the T-level or the M-level. Furthermore, the correlation between the insertion depth and stimulation levels was not affected by the duration of deafness, age at implantation or the time since implantation. Additionally, the T-levels showed a significant correlation with the speech perception scores $(p<0.05)$. Conclusions: The stimulation levels of the cochlear implants were affected by the intracochlear position of the electrode contacts, which were determined using postoperative CT scanning. Interestingly, these levels depended on the insertion depth, whereas the distance to the modiolus did not affect the stimulation levels. The T-levels increased toward the basal end of the cochlea. The level profiles were independent of the overall stimulation levels and were not affected by the biographical data of the patients, such as the duration of deafness, age at implantation or time since implantation. Further research is required to elucidate how fitting using level profiles with an increase toward the basal end of the cochlea benefits speech perception. Future investigations may elucidate an explanation for the effects of the intracochlear electrode position on the stimulation levels and might facilitate future improvements in electrode design.

(C) 2016 The Author(s)

Published by S. Karger AG, Basel

Feddo B. van der Beek, MD

Department of Otolaryngology, Medical Spectrum Twente PO Box 50000

NL-7500 KA Enschede (The Netherlands)

E-Mail f.vanderbeek@mst.nl 


\section{Introduction}

Cochlear implants provide useful speech perception for many recipients. The variation in performance, however, is large and in many cases unexplained. Different biographical and audiological factors concerning the patient (the duration of deafness and preoperative speech perception scores) are known to affect postoperative performance [Blamey et al., 2013; Holden et al., 2013]. Additionally, factors concerning the neuron-electrode interface play a role in the postoperative performance. Factors affecting this interface include the distance to the modiolus, the amount and density of excitable nerve fibers, the amount of fluid surrounding the electrode and the presence of scar tissue. Several studies have shown that the intracochlear electrode position is correlated with speech perception scores [Finley et al., 2008; Holden et al., 2013; van der Beek et al., 2005]. The relationship between the intracochlear electrode position and the outcomes of cochlear implantation appears to be a reflection of the efficacy of the transfer of the electrical stimulus to the nerve fibers. The efficacy of stimulation is determined not only by patient-dependent factors but also by the manner in which the electrical signal is presented [Wilson et al., 1991]. The manner in which the signal is presented along the array is established for each individual during the fitting procedure. In this study, the effects of the intracochlear position (the distance to the modiolus and the insertion depth) on the fitting levels of cochlear implant recipients were investigated, and the results provide insights for improving future device fittings and designs.

During implant fitting, many parameters can be set; however, the threshold levels (T-levels) and maximum comfort levels (M-levels) along the array continue to be the core parameters that are defined. Although the levels are implemented differently, and different units and names are used by each cochlear implant manufacturer, an upper limit for electrical stimulation per active electrode contact is always defined. For readability, the maximum and most comfortable levels (called the M-level, C-level, and MCL by manufacturers) will be referred to as M-levels throughout this manuscript. Previous studies have demonstrated that there is a certain level of conformity in the M- and T-level profiles, both of which tend to increase toward the basal end of the cochlea [Smoorenburg, 2007]. This increase has been observed for cochlear implants produced by different manufacturers (Cochlear Corp., Lane Cove, Australia; Advanced Bionics, Sylmar, Calif., USA; MedEl Corp., Innsbruck, Austria) [Baudhuin et al., 2012; Botros and Psarros, 2010; Cafarelli et al., 2005;

Intracochlear Position of Cochlear Implants: CT Scanning vs. Fitting Levels
D’Elia et al., 2012; Lai et al., 2009; Miller et al., 2008; Polak et al., 2005; Smoorenburg et al., 2002; Thai-Van et al., 2001; van der Beek et al., 2015; Vargas et al., 2013]. Furthermore, both perimodiolar and more lateral electrodes (Nucleus Straight vs. Contour) show higher levels basally [Polak et al., 2004]. However, these studies did not determine whether there was a direct correlation between these levels and the exact location of the electrode array within the cochlea and thus the distance to the targeted nerve fibers.

Using CT scanning, the intracochlear position of individual contacts can be visualized, and the electrode-modiolus distance and the insertion depth of each electrode can be measured [Ruivo et al., 2009; van der Beek et al., 2005; van Wermeskerken et al., 2009; Verbist et al., 2008, 2010a]. The positions of cochlear implant electrode contacts can be visualized rather accurately. Verbist et al. [2008] showed that mean differences between the known geometry of a phantom cochlear implant and CT-based measurements was $0.09-0.18 \mathrm{~mm}$ for 4 different multisection CT systems. Additionally, O’Malley et al. [2014] showed that insertion measurements with histological 3D reconstruction and CT imaging differed less than $1 \%$. However, the effects of the cochlear position of the implant, as determined using postoperative CT scanning, on the clinical stimulation levels have been investigated in only a few studies. Some authors describe that the contribution of the distance to the modiolus or the insertion depth on levels could not be clearly determined [Long et al., 2014; van der Beek et al., 2005]. Other authors, however, indicate that radiological imaging can be used as a possible technique for retrieving additional data regarding processor fitting in individual patients, with which even improving hearing outcomes can be obtained [Noble et al., 2013].

Additional evidence confirms that the distance to the modiolus affects the neuron-electrode interface. Shepherd et al. [1993] studied animal models and found that approximating the stimulating electrode to the modiolus resulted in lower stimulation levels. Perimodiolar approximation is thought to improve the efficacy of stimulation. However, although Saunders et al. [2002] showed that perimodiolar-designed electrode arrays decreased the T- and M-levels, the dynamic range (DR) did not increase as predicted. Additionally, others could not confirm that perimodiolar approximation led to lower T-levels [Huang et al., 2006; Long et al., 2014; Marrinan et al., 2004; van der Beek et al., 2005]. Kawano et al. [1998], however, showed a correlation between the distance from the electrode to Rosenthal's canal using histological spec- 
imens and the level profile. The distance to the modiolus is affected by the design and placement of the electrode array. In addition to these electrode-dependent factors, the difference in the diameters of the scalae, which have a clearly smaller scalar diameter at the apical end compared with the basal end, potentially affects the distance from the electrode to the modiolus [Rebscher et al., 2008]. In addition to the scalar diameter, the cochlea exhibits other obvious anatomical differences (e.g. the thickness of the osseous spiral lamina) in subsequent turns. However, although the anatomy of the basal versus the more apical cochlear turns differs considerably, no study has investigated the relationship between the distance between the modiolus and the electrode contacts and the corresponding stimulation levels at different insertion angles.

The variation in the numbers of surviving neurons along the cochlea was proposed as another possible explanation for the position-related differences in the stimulation level profile. Nadol [1997] demonstrated that spiral ganglion cell (SGC) degeneration was more severe at the basal end of the cochlea than in the apical turn. Additionally, Polak et al. [2004] found larger elicited compound action potential threshold (ECAP) amplitudes and amplitude growth curves apically in the cochlea and attributed these to the different SGC densities throughout the cochlea. Propst et al. [2006] also argued that the stimulation differences observed along the array were caused by the unequal distribution of degenerated neurons because the etiology most likely to account for uniform neuronal damage along the cochlea (GJB2) did not show ECAP amplitude differences along the array [Propst et al., 2006]. Furthermore, Long et al. [2014] showed that the degree to which the distance between the electrode and the modiolus could predict the T-levels correlated with the speech perception scores, and they argued that differences in the content of neural elements along the cochlea caused these variations. Researchers have also assumed that the excitation width of the commonly used monopole stimulation mode averages out small variations in the level profile [Bierer and Faulkner, 2010].

To explain the less efficient basal stimulation, other researchers have noted the difference in impedance caused by the larger volume of fluid near the basal electrodes [van Wermeskerken et al., 2009] or by the basal current path through the round window [Micco and Richter, 2006; van der Beek et al., 2005]. Furthermore, cochlear damage at the time of implantation and the resulting formation of new tissue and bone might negatively affect the neuron-electrode interface. Adunka et al.
[2004] reported that the cochleostomy procedure caused destructive trauma to the cochlea. Additionally, Li et al. [2007] reported the formation of new fibrous tissue, mainly at the basal end of the cochlea. Other researchers confirmed that most of the new intracochlear fibrous tissue formation occurred at the basal end of the cochlea [Fayad et al., 2009]. Moreover, Kawano et al. [1998] showed that intracochlear fibrous tissue and bone growth was correlated with T-levels.

The value of basal stimulation in speech perception was shown by Finley et al. [2008], who reported that bypassing the basal part of the cochlea had a detrimental effect on speech perception. This correlation may be related to the fact that the ECAP measures showed a smaller spread of excitation in the basal cochlea compared with the apical portion [Eisen and Franck, 2005; van der Beek et al., 2012]; however, the psychophysical tuning curves did not confirm this difference in spatial selectivity along the array [Nelson et al., 2011].

The goal of this study was to show the effect of the intracochlear position of cochlear implants on the clinical fitting levels. The analyses were performed for all of the individual contacts, thus spanning the first and part of the second turn of the cochlea, using the angular location and the distance to the modiolus as the parameters. In our center, the M-levels were fitted using a preset profile with an increase at the basal end of the cochlea in an attempt to improve speech understanding under noisy conditions by enhancing the high-frequency information [Frijns et al., 2002]. Therefore, the M-levels established in our center were not suitable for investigating the effect of the intracochlear position on these levels. Furthermore, even without using a preset profile, M-levels are not objective measures that can be used to study correlations with intracochlear positions because the perception of maximum comfort is highly subjective. To ensure the patient's comfort and to avoid sharp-pitched sounds, some audiologists lower the basal M-level during fitting. In centers in which the M-levels are set without an increase toward the basal end [Wesarg et al., 2010], the DR will substantially decrease basally. Due to the preset profile used to determine the M-levels used in our clinic, no further conclusion from either M-levels or DR could be drawn from this study. Moreover, only the T-levels, in contrast to the M-levels, show a firm correlation with the degree of speech perception [van der Beek et al., 2015], and most of the correlations described in the present study were discovered using the T-levels.

Additionally, the correlations between the duration of deafness, age at implantation and time since implantation
56

Audiol Neurotol 2016;21:54-67 DOI: $10.1159 / 000442513$ van der Beek/Briaire/van der Marel/ Verbist/Frijns 
and the stimulation levels at different angles of insertion in the cochlea were determined to provide further insight into the factors that affect the efficacy of the neuron-electrode interface. Implications for fitting are discussed, as are possibilities for future research and electrode development.

\section{Materials and Methods}

\section{Subjects}

The clinical data for 130 postlingually deafened adult cochlear implant recipients who used either a CII or an electrically identical HiRes 90K cochlear implant with a fully inserted HiFocus 1/1J electrode array (Advanced Bionics) were analyzed in this study. These subjects were consecutively implanted between 2002 and 2008 at the Leiden University Medical Center. Two surgeons performed all of the implantations during this period. An extended round-window insertion was performed in all cases. Subjects younger than 16 years old were not included in this study. The demographic information for the subjects is summarized in table 1 . All of the subjects used the HiRes processing strategy. For a variety of reasons, 36 postlingually deafened adult subjects who were implanted during this period were excluded from the study (table 2), mainly because of a lack of reconstructable CT data (see below).

\section{Intrascalar Position}

All of the implanted patients received a postoperative CT scan to confirm that the cochlear implant had been properly inserted. To analyze the intrascalar position, serial multiplanar reconstructions were executed [Verbist et al., 2005]. The insertion angle and the position of each electrode contact were determined using a 3D coordinate system based on international consensus [Verbist et al., 2010a, b] and an in-house designed postprocessing program (MATLAB; MathWorks, Novi, Mich., USA; fig. 1). The accuracy of this method in measuring the rotational angle and the distance to the modiolus was validated previously [Verbist et al., 2010a]. Because the scanning protocol was in development during the first inclusion period, 17 subjects had CT scans that were not of sufficient quality to allow multi-planar reconstructions. Those patients were not included in this study (table 2).

\section{Stimulation Levels}

All of the patients were fitted with the (monopolar) HiRes strategy. Both the T-level and the M-level were determined during regular clinical fitting sessions that took place approximately 8 times during the first year. The T- and M-levels obtained at the 1 -year follow-up were used in this study. Additionally, to evaluate the effects of time on the levels, the levels observed at the initial fitting were included in the data set. The T-levels were measured separately for each active electrode contact while delivering a 300-ms pulse train of biphasic pulses in an up-down-up procedure. For each electrode contact, the stimulus levels were increased, starting at 0 linear clinical units (CU), until the subjects indicated that they heard a sound. Next, the current was increased above this approximate $\mathrm{T}$-level to provide a clearly audible percept on which the subject could focus. The level was then decreased again until the subject indicated that he or she did not

Intracochlear Position of Cochlear Implants: CT Scanning vs. Fitting Levels

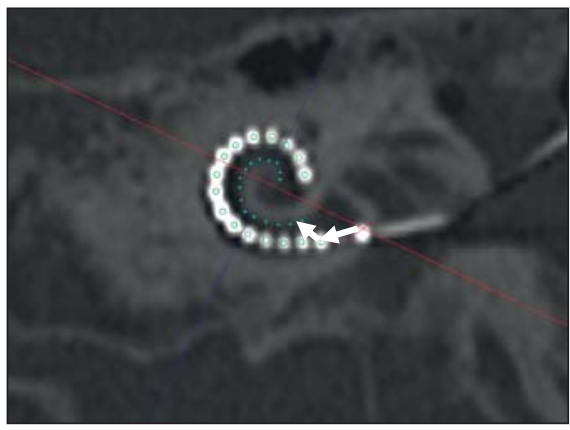

Fig. 1. Multiplanar reconstruction of a postimplantation CT scan showing the intracochlear location of the individual contacts. The arrows indicate the distance to the modiolus and the insertion depth of the most basal electrode contact.

Table 1. Patient demographics

\begin{tabular}{ll}
\hline Patients, $\mathrm{n}$ & 130 \\
Age, years & $56(17-84)$ \\
$\begin{array}{l}\text { Duration of deafness, years } \\
\text { Sex, } \mathrm{n}\end{array}$ & $22(0.1-60)$ \\
$\quad$ Male & 47 \\
$\quad$ Female & 83 \\
Implant type & CII/HiRes 90K HiFocus 1/1J \\
Etiology, $\mathrm{n}$ & \\
$\quad$ Progressive & 100 \\
$\quad$ Medication & 4 \\
$\quad$ Ménière's disease & 5 \\
$\quad$ Meningitis & 12 \\
$\quad$ Otosclerosis & 4 \\
$\quad$ Trauma & 3 \\
$\quad$ Usher syndrome & 2 \\
Monosyllabic word score at & \\
$\quad$ 1 year, \% & $57(5-93)$ \\
\hline
\end{tabular}

Data are presented as average values with ranges in parentheses, unless otherwise indicated.

Table 2. Number of implanted patients excluded from the study

\begin{tabular}{ll}
\hline Patients excluded from study & Number \\
\hline Mentally handicapped & 5 \\
Non-Dutch speaker & 1 \\
Deceased, natural cause & 3 \\
Facial-nerve stimulation & 1 \\
Incomplete insertion & 2 \\
Device failure & 3 \\
No follow-up level data available & 4 \\
Could not reconstruct CT data & 17 \\
\hline Total & 36 \\
\hline
\end{tabular}


hear the sound. Then, the level was decreased somewhat further to reach a definite subthreshold level. Finally, the level was increased again to determine the final T-level. To determine the M-levels at the initial fitting, a profile was introduced with an emphasis up to $25 \% \mathrm{CU}$ for the more basal electrode contacts: the electrode numbering in Advanced Bionics devices is from apical (1) to basal (16). Subsequently, the processor was set to livespeech mode, live speech at a normal voice level was administered to the subject, and all of the M-levels were increased simultaneously until speech was reported to be comfortably loud. At this time, the subject was asked to assess the sound quality. First, an open question was asked, but if needed, adjectives (e.g. lowpitched, muffled, high-pitched or sharp) were suggested to help the patient to describe the sound quality. If the percept had a very low or muffled quality, the M-levels of the apical electrodes were reduced while a smooth $\mathrm{M}$-level profile was maintained. If the sound was described as too sharp, the slope of the M-level profile was lowered until the patient accepted the sound quality; however, the slope was never lower than a straight horizontal line [Briaire and Frijns, 2008].

For most of the subjects, 12 electrodes were active, but one-fifth of the subjects were fitted with fewer active electrodes. In most cases, the rationale for using 12 active electrodes was based on the results of previous research [Frijns et al., 2003]. Following the convention used by Advanced Bionics, the levels were expressed on a linear scale in clinical units: pulse width (microseconds) $\times$ amplitude (microamperes) $\times 0.0128447$. Additionally, the data were recalculated and expressed in decibels, as follows: 1 (decibels) $=20$ $\log (\mathrm{l}(\mathrm{CU}) / 1,000 \times 20.6(\mathrm{CU}))$ [Pfingst and $\mathrm{Xu}, 2005]$.

\section{Speech Perception}

Speech discrimination scores were obtained during normal clinical follow-up sessions that occurred at predetermined intervals. The scores obtained at the 1-year follow-up were analyzed in this study. The standard Dutch speech test of the Dutch Society of Audiology, consisting of phonetically balanced monosyllabic (CVC: consonant-vowel-consonant) lists of words, was used [Bosman and Smoorenburg, 1995]. The speech tests were performed in a free field using a speech signal of $65 \mathrm{~dB} \mathrm{HL}$, as previously described [van der Beek et al., 2005].

\section{Statistics}

SPSS 19 software (IBM Corp., Armonk, N.Y., USA) was used for the regression analysis and to test the differences among the mean values ( $t$ test). Local regression (LOESS) fits were used to optimize the fitting for all of the loci along the electrode array. To obtain a regression function that could be easily represented using a mathematical formula, mixed linear models were used to obtain quadratic fits.

\section{Results}

Table 3 shows the intrascalar positions of the electrode contacts along the array. The mean insertion depth and the distance to the modiolus from each of the electrode contacts were measured. The mean insertion depth of the most apical electrode (1) was $472^{\circ}\left(\mathrm{SD} 73.8^{\circ}\right)$. Figure 2

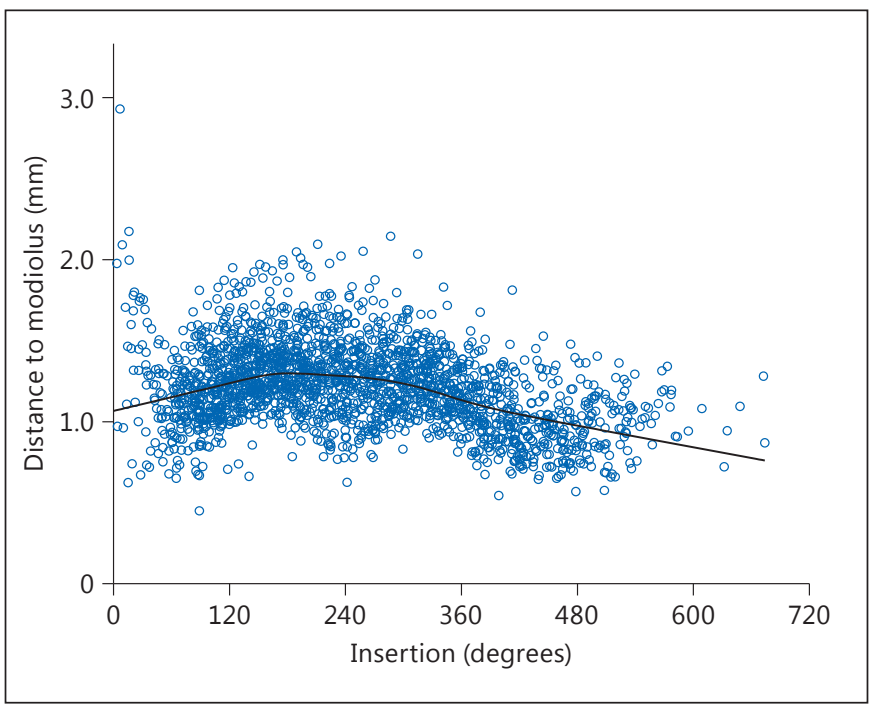

Fig. 2. The distance to the modiolus of each individual electrode contact plotted against the insertion depth. A LOESS fit is shown.

Table 3. Mean insertion angles and distances to the modiolus of electrodes 1 (apical) to 16 (basal)

\begin{tabular}{rll}
\hline Electrode & $\begin{array}{l}\text { Insertion angle, } \\
\text { degrees }\end{array}$ & $\begin{array}{l}\text { Distance to modiolus, } \\
\mathrm{mm}\end{array}$ \\
\hline 1 & $472.32 \pm 73.77$ & $1.01 \pm 0.22$ \\
2 & $433.47 \pm 69.03$ & $1.04 \pm 0.23$ \\
3 & $397.55 \pm 64.09$ & $1.10 \pm 0.24$ \\
4 & $363.49 \pm 58.85$ & $1.16 \pm 0.24$ \\
5 & $332.41 \pm 54.72$ & $1.22 \pm 0.25$ \\
6 & $303.25 \pm 51.57$ & $1.26 \pm 0.22$ \\
7 & $275.14 \pm 48.28$ & $1.27 \pm 0.21$ \\
8 & $248.46 \pm 46.11$ & $1.29 \pm 0.23$ \\
9 & $222.54 \pm 43.67$ & $1.29 \pm 0.25$ \\
10 & $198.07 \pm 41.61$ & $1.27 \pm 0.24$ \\
11 & $175.10 \pm 39.81$ & $1.28 \pm 0.25$ \\
12 & $153.00 \pm 38.00$ & $1.30 \pm 0.22$ \\
13 & $131.91 \pm 36.16$ & $1.30 \pm 0.22$ \\
14 & $111.69 \pm 34.92$ & $1.26 \pm 0.23$ \\
15 & $92.06 \pm 33.26$ & $1.20 \pm 0.25$ \\
16 & $72.45 \pm 31.12$ & $1.22 \pm 0.32$ \\
\hline
\end{tabular}

Data are presented as means $\pm \mathrm{SD}$. shows that the distance to the modiolus from the basal electrode contacts was smaller than that of the contacts that had been inserted at three-quarters of a turn $\left(270^{\circ}\right)$. The contacts with an insertion angle beyond this point were also a shorter distance from the modiolus. Statistical 


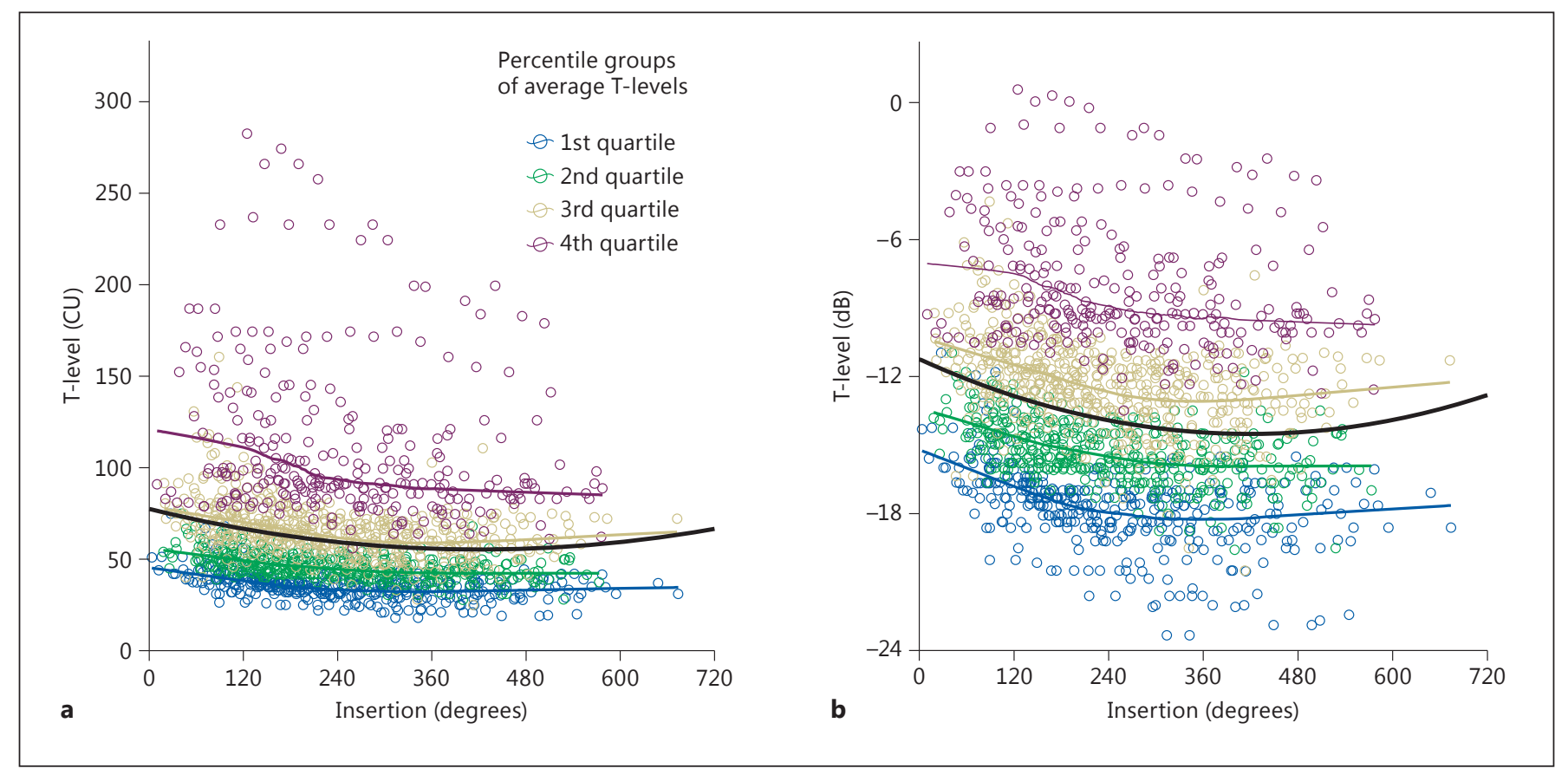

Fig. 3. Scatter plot of the individual T-levels per electrode contact, expressed in CU (a) and in decibels (b), vs. the insertion depth. The population was divided into percentile groups according to the overall T-levels, and the fits for the subgroups are shown (lowest quartile: blue; lower-middle quartile: green; upper-middle quartile: yellow; upper quartile: fuchsia). The black fitting line is the quadratic fit for the entire population.

analysis using Student's t test showed that these variations in the modiolar distance along the array were significant (table 4).

The scatter plots in figure 3 show the T-levels versus the insertion depths expressed in CU (fig. 3a) and in decibels (fig. 3b). A large variation in the levels can be observed. The population was divided into 4 percentile groups based on their average T-levels. For each percentile group, a LOESS fit is shown in the same colors as the data points. Furthermore, the quadratic fit for the total group is shown in black. An increase in the T-levels toward the basal end is clearly visible in all of the (sub) groups. Toward the apical end, a flat profile or a minor increase was observed. Whereas figure 3 a shows different degrees of increase in the T-levels toward the basal end, converting the data to decibels (fig. $3 \mathrm{~b}$ ) shows that this basal increase was comparable in all 4 of the percentile groups. The quadratic fit for the population as a whole showed an increase of $3.4 \mathrm{~dB}$.

Table 5 shows the speech perception scores for the 4 percentile groups according to their overall T-levels. The percentile group with the lowest T-levels showed significantly better speech perception (68.9\% word score) com- pared with the other percentile groups, whereas the percentile group with the highest T-levels showed the worst speech perception scores (44.2\% word score).

Figure 4a shows the scatterplot of the distance to the modiolus versus the T-levels for all of the individual electrode contacts. Clearly, there was no significant correlation between the distances to the modiolus and the Tlevels $(p=0.12)$. Furthermore, the distance to the modiolus was not significantly correlated with the T-levels for different sections of the cochlea. Figure $4 \mathrm{~b}$ and $\mathrm{c}$ shows the data for two random subsections, $90-150^{\circ}$ and 330 $390^{\circ}$, and the lack of a significant correlation ( $\mathrm{p}=0.6$ and $\mathrm{p}=0.9$, respectively). The word scores of the patients were not significantly correlated with the distance between the modiolus and the array ( $\mathrm{a}$ trend is seen, though not significant, $\mathrm{p}=0.06$ ) or the insertion depth of the array ( $\mathrm{p}=$ $0.8)$.

Figure 5 shows the fits of the T-levels (fig. $5 \mathrm{a}$; previously shown in fig. 3b), M-levels (fig. 5b) and DRs (fig. 5c) for the percentile groups and the entire population. As was found for the T-levels, the M-levels of the entire population increased toward the basal end (T-levels: 3.4 $\mathrm{dB}$; M-levels: $1.3 \mathrm{~dB}$ ), consistent with the fact that the 


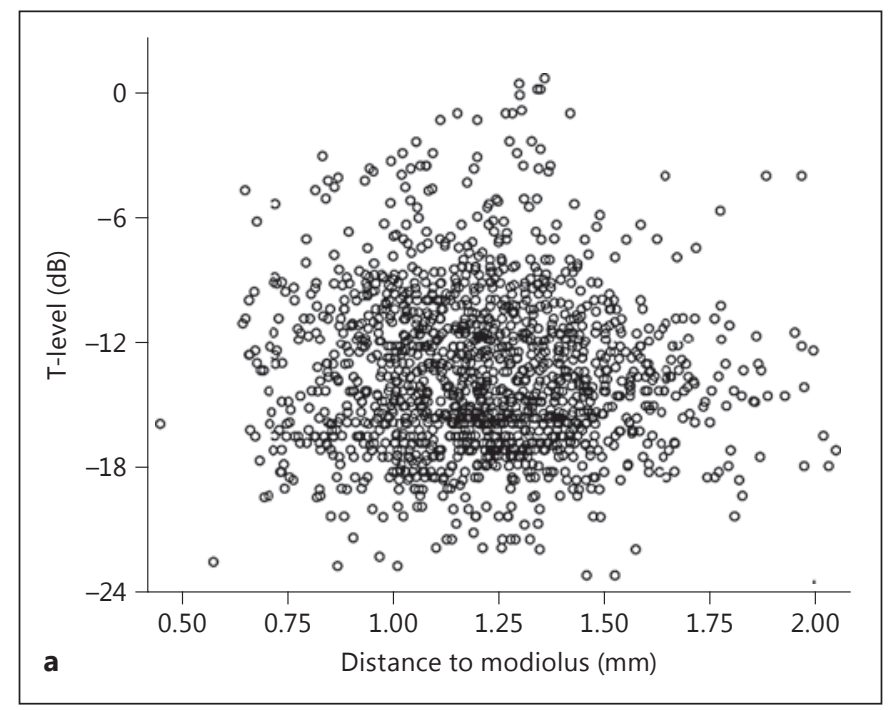

Fig. 4. Scatter plot of the individual T-levels per electrode contact vs. the distance to the modiolus. a All electrodes. $\mathbf{b}$ Electrodes inserted between 90 and $150^{\circ}$. c Electrodes inserted between 330 and $390^{\circ}$.

Table 4. Mean distance to the modiolus from different parts of the cochlea

Part of cochlea
\begin{tabular}{llll}
\hline $0-120^{\circ}$ & $120-240^{\circ}$ & $240-360^{\circ}$ & $>360^{\circ}$ \\
$(\mathrm{A})$ & (B) & (C) & (D)
\end{tabular}

\section{Distance to}

modiolus, $\mathrm{mm} \quad 1.19 \pm 0.27 \quad 1.32 \pm 0.23 \quad 1.26 \pm 0.21 \quad 1.01 \pm 0.20$ Significant
differences
$\mathrm{D}$
A, C, D
A, D

Data are presented as means \pm SD. Significant $(p<0.05)$ differences in pairwise comparisons of the column mean values are indicated under the category with the larger mean value.
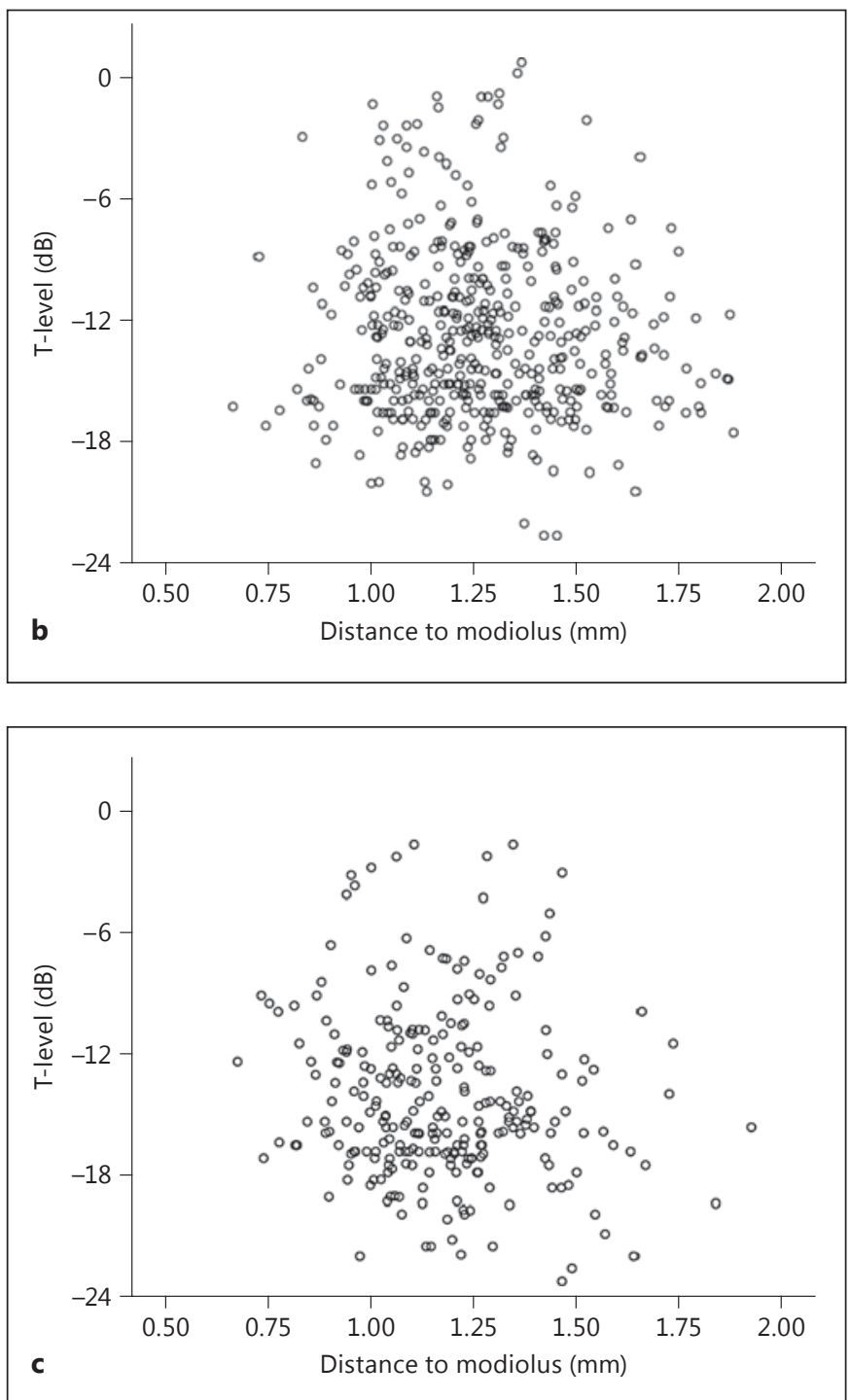

Table 5. Speech perception scores for the 4 percentile groups according to the overall T-levels

\begin{tabular}{lllll}
\hline & \multicolumn{4}{l}{ Percentile group according to the T-levels } \\
\cline { 2 - 5 } & $\begin{array}{l}1 \\
(0-25 \%)\end{array}$ & $\begin{array}{l}2 \\
(26-50 \%)\end{array}$ & $\begin{array}{l}(51-75 \%) \\
(76-100 \%)\end{array}$ & $\begin{array}{l}4 \\
\end{array}$ \\
\hline $\begin{array}{c}\text { Word scores, \% } \\
\begin{array}{c}\text { Significant } \\
\text { differences }\end{array}\end{array}$ & $68.9 \pm 15.5$ & $51.9 \pm 24.3$ & $51.5 \pm 15.5$ & $44.2 \pm 28.1$ \\
$\begin{array}{c}\text { T-levels, CU } \\
\text { Significant } \\
\text { differences }\end{array}$ & $35.3 \pm 7.0$ & $46.2 \pm 6.9$ & $62.8 \pm 12.6$ & $102.6 \pm 40.8$ \\
\hline
\end{tabular}

Data are presented as means \pm SD. Significant $(\mathrm{p}<0.05)$ differences in the pairwise comparisons of the column mean values are indicated under the category with the larger mean value.
60 van der Beek/Briaire/van der Marel/ Verbist/Frijns 

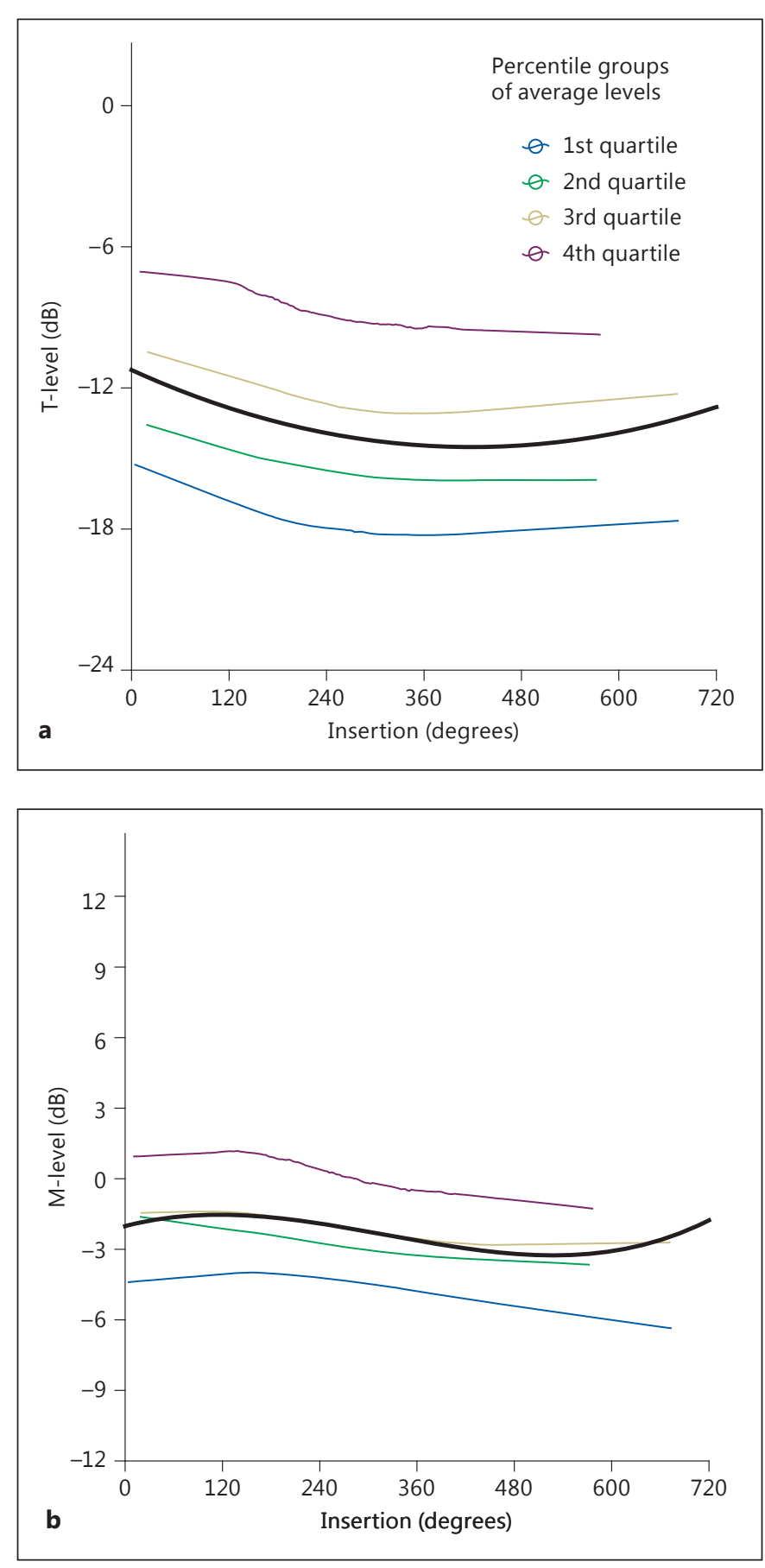

M-levels in our population were established using a preset profile with an emphasis on the basal electrodes. However, for the lowest 3 percentile groups, the increase in the M-levels toward the basal end was smaller than the increase in the T-levels, resulting in decreased average basal DRs (average $2.1 \mathrm{~dB}$; fig. 5c). The percentile group

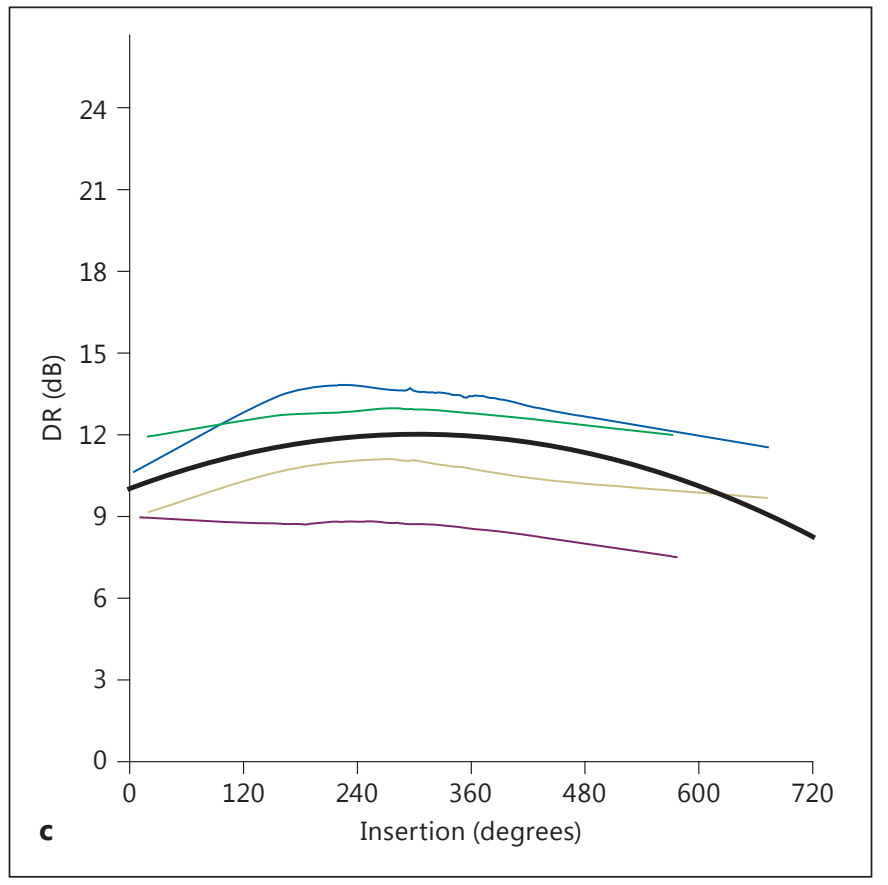

Fig. 5. The LOESS fitting lines of the quartile groups according to the overall T-levels (a), M-levels (b) and DR (c). The black fitting line is the quadratic fit for the entire population.

with the highest T-levels did not show this decrease in the DR. Additionally, as figure $5 \mathrm{c}$ shows, the subjects in the percentile group with the lowest $\mathrm{T}$-levels had the highest DR (13.6 dB, SD 2.6), and the percentile group with the highest T-levels had the smallest $\mathrm{DR}(9.5 \mathrm{~dB}, \mathrm{SD} 3.2)$. The basal increases in the T-levels of the 4 subgroups were not 


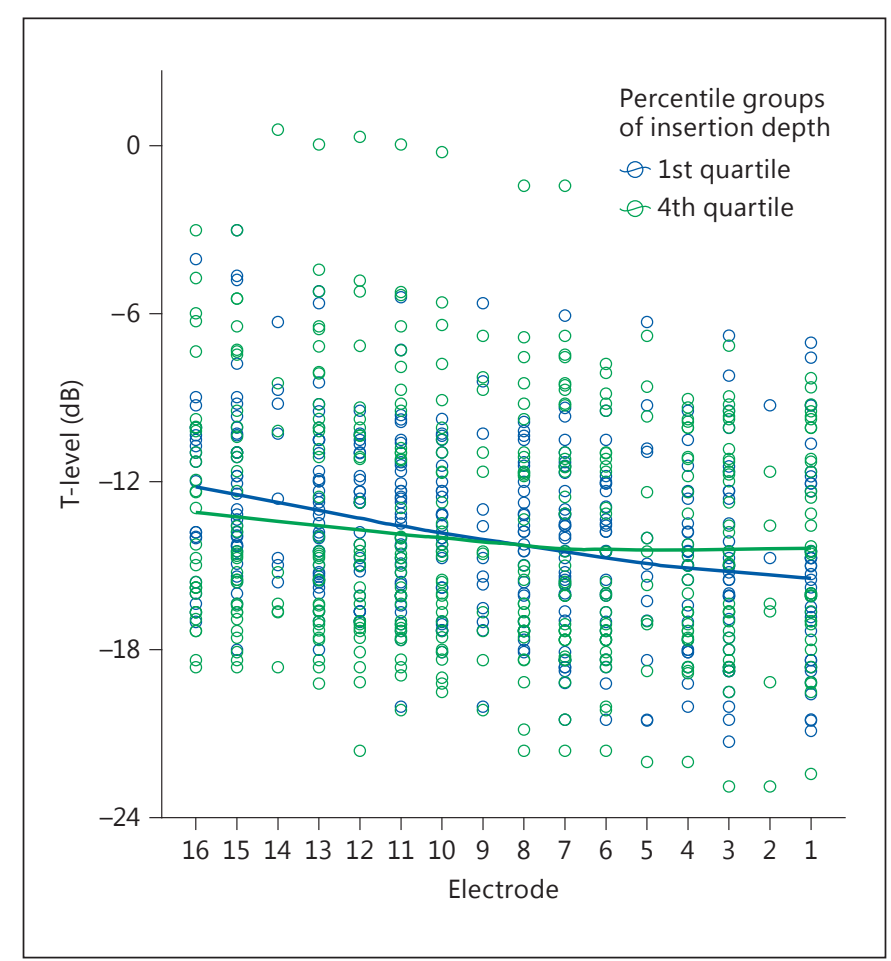

Fig. 6. Scatter plot of the T-levels per electrode contact for the subgroups with the $25 \%$ most shallowly and $25 \%$ most deeply inserted electrodes (table 6).

significantly different $(p>0.12)$. It is important to notice once more that the M-levels were determined with a preset profile and were not measured for individual electrode contacts. Subsequently, the DR was not based on only measured data, but was determined by the measured T-levels and the M-levels with the mentioned preset profile.

Figure 6 shows the data for the $25 \%$ of subjects with the most deeply inserted electrode arrays and the 25\% with the most shallowly inserted arrays. The electrode contacts rather than the insertion angles are plotted on the $\mathrm{x}$-axis to mimic the representation of the T-levels that was obtained using the clinical fitting software. The most deeply inserted arrays did not show a significant increase in the T-levels along the array, whereas the most shallowly inserted arrays showed significant differences in the levels along the array $(2.9 \mathrm{~dB}, \mathrm{p}<0.05)$.

Figure 7a shows the scatter plots of the T-levels versus the insertion depth for the subgroups of the $50 \%$ of patients with the shortest (blue, mean 7.0 years, SD 4.4) and the $50 \%$ with the longest durations of deafness (green, mean 37.0 years, SD 13.4). The mean T-levels of the 2 sub-
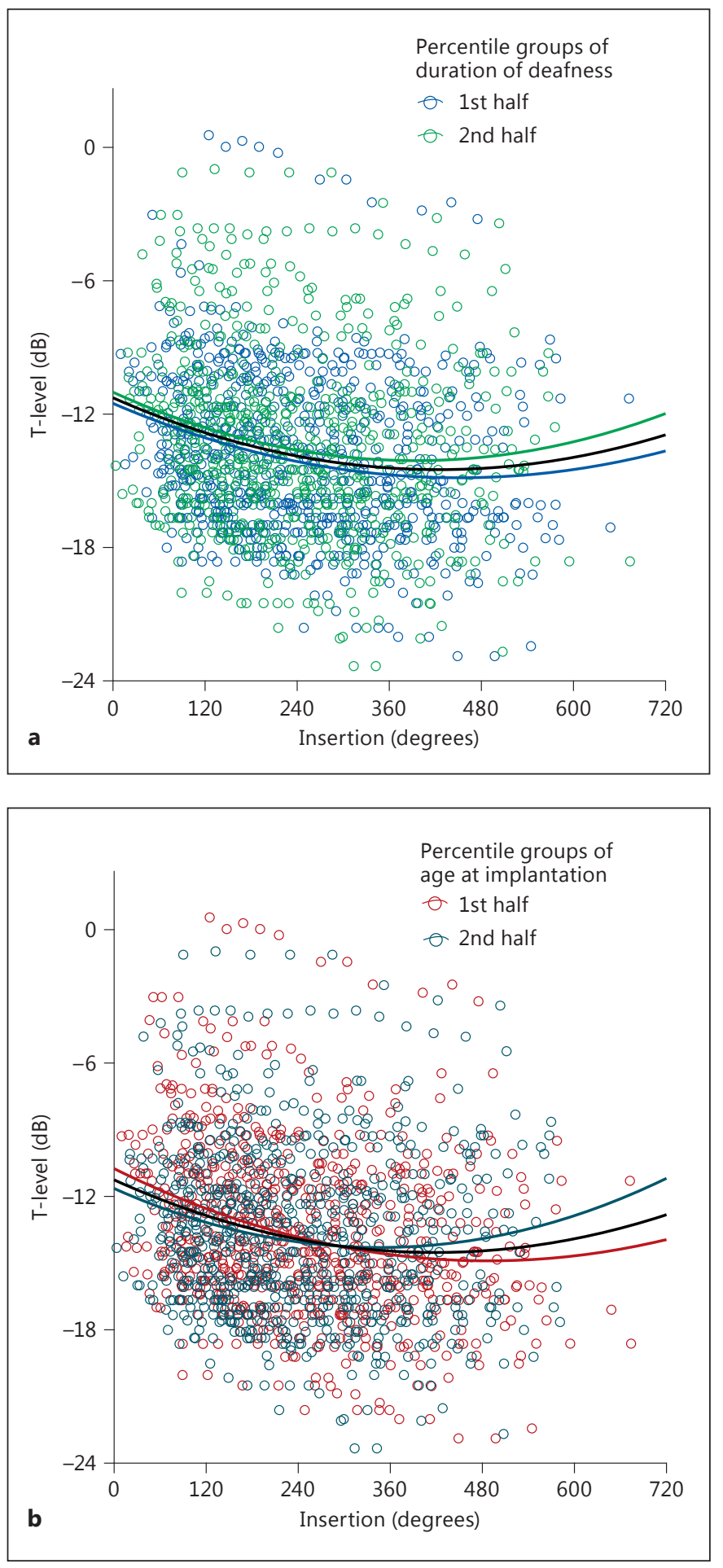

Fig. 7. a The T-levels vs. the insertion depth for 2 sub-groups comprising the half of the patients with the longest (blue) and shortest (green) durations of deafness, showing the fits of the subgroups and the overall fit. $\mathbf{b}$ The T-levels vs. the insertion depth for the 2 subgroups of the half of the patients with higher (red) and lower (blue) ages at implantation, showing the fits of the subgroups and the overall fit. van der Beek/Briaire/van der Marel/ Verbist/Frijns 


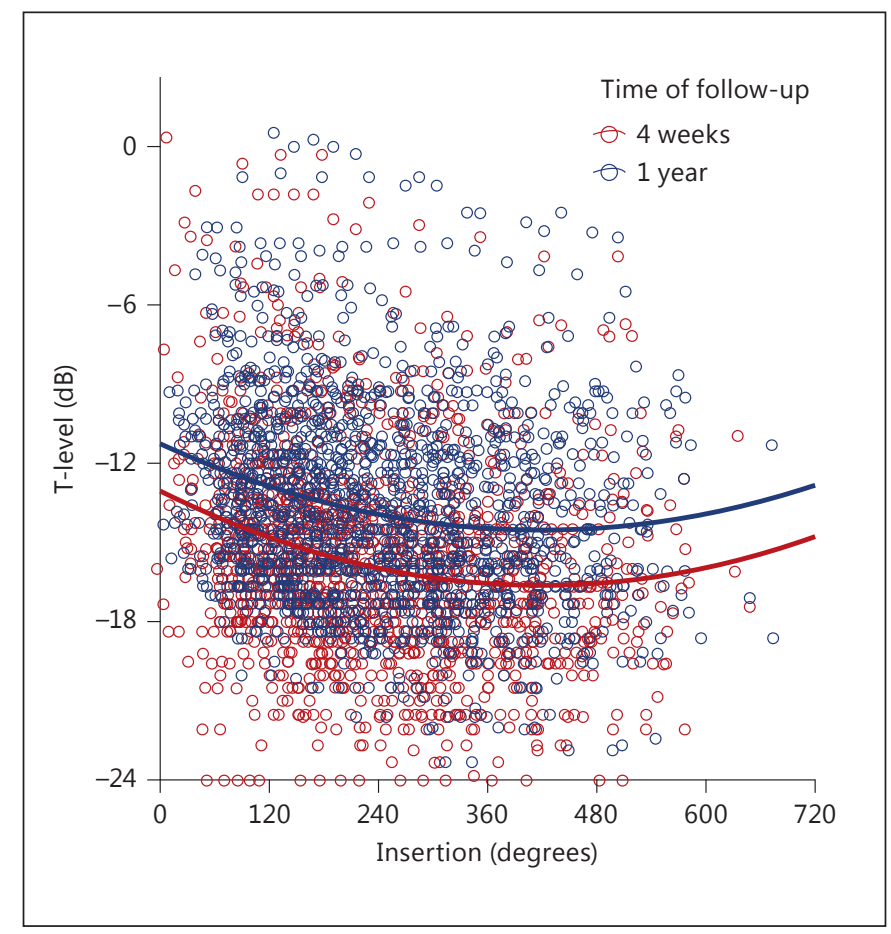

Fig. 8. The T-levels vs. the insertion depths at the initial fitting (red) and after 1 year of cochlear implant usage (blue). The fits are shown in matching colors.

groups were not significantly different (mean $-13.8 \mathrm{~dB}$, SD 3.7; mean $-13.4 \mathrm{~dB}, \mathrm{SD} 3.7, \mathrm{p}=0.53$ ). Furthermore, the quadratic fits showed that the increase toward the basal end was not significantly different for the 2 subgroups ( 3.2 vs. $3.4 \mathrm{~dB}, \mathrm{p}=0.17$ ). Figure $7 \mathrm{~b}$ shows the $\mathrm{T}$-levels versus the insertion depth for the subgroups comprising the 50\% of patients with the lowest (red, mean 44.2 years, SD 10.2) and the $50 \%$ of patients with the highest age at implantation (blue, mean 67.9 years, SD 6.6). The mean T-levels did not significantly differ (mean $-13.5 \mathrm{~dB}$, SD 3.5; mean $-13.6 \mathrm{~dB}, \mathrm{SD} 3.8, \mathrm{p}=0.29$ ), and the basal increases were comparable (3.3 vs. $3.4 \mathrm{~dB}$ ) and not significantly different $(\mathrm{p}=0.18)$. Despite the similarities in the T-levels, as shown in figure $7 \mathrm{a}$ and $\mathrm{b}$, the speech perception scores of the 2 subgroups based on the duration of deafness (mean 59.8\%, SD 21.5; mean 53.3\%, SD 21.4) or the age at implantation (mean 59.9\%, SD 21.2; mean 54.1\%, SD 21.2) were significantly different $(\mathrm{p}<0.05)$.

Figure 8 clearly shows that the T-levels were higher overall after 1 year of cochlear implant use (blue) than at the first fitting (red; $-13.6 \mathrm{~dB}, \mathrm{SD} 3.7$ vs. $-15.5 \mathrm{~dB}, \mathrm{SD} 3.8$, $\mathrm{p}<0.01$ ), but the profile along the cochlea remained es-

Intracochlear Position of Cochlear Implants: CT Scanning vs. Fitting Levels sentially unaltered. No significant differences in increase in T-levels along the array were observed between the data at 1 year and at the first fitting $(\mathrm{p}=0.09)$.

\section{Discussion}

Clinical research has shown a correlation between the DR and speech perception that endorses the need for setting the proper fitting levels for cochlear implants [Blamey et al., 1992; Pfingst and Xu, 2005; Pfingst et al., 2004; van der Beek et al., 2015]. The aim of the present study was to determine whether radiological data provided additional information for setting the speech processor map levels. Therefore, the intrascalar positions of individual cochlear implant electrode contacts were determined according to the CT scans of 130 postlingually deafened subjects, and their correlations with the clinical fitting levels along the array were studied. Interestingly, the fitting levels did not show any correlation with the distance between the electrode contacts and the modiolus. Speech perception was not significantly correlated with the insertion depth or the distance from the electrode array to the modiolus. Furthermore, the increase in levels at the basal end of the array was not significantly correlated with the subjects' mean stimulation level, duration of deafness, age at implantation or time since implantation.

Clearly, the angular location of an electrode contact affects its T-level (fig. 3), and whether the additional knowledge obtained from a radiological analysis would help with fitting the patient was considered. A previous study [van der Beek et al., 2015] showed that T-levels could be fitted by determining the $\mathrm{T}$-level at one electrode contact and applying a closed-set formula for the T-level profile based on group data. Adding radiological data to such a model might further increase the applicability of this approach for clinical programming. Two subgroups were created that included the $25 \%$ of subjects with the most shallowly inserted electrodes and the $25 \%$ with the most deeply inserted electrodes (table 6). Figure 6 shows that the insertion depth of the array significantly affected the T-level profile. This effect was further analyzed by adding the insertion depth to the population-based predictive formula for the levels [van der Beek et al., 2015]. Although this process yielded a significant parameter, it did not increase the predictability of the levels (data not shown).

The lack of correlation between the T-level and the distance to the modiolus (fig. 4) precluded the use of this radiological parameter when setting the fitting lev- 
Table 6. The insertion depths of the most apical electrode (1) and the most basal electrode (16) of the subgroups of the $25 \%$ most shallowly inserted electrode arrays and the $25 \%$ most deeply inserted arrays

\begin{tabular}{|c|c|c|}
\hline \multirow[t]{2}{*}{ Electrode } & \multicolumn{2}{|l|}{ Percentile group } \\
\hline & $\begin{array}{l}25 \% \text { shallowest } \\
\text { insertions }\end{array}$ & $\begin{array}{l}25 \% \text { deepest } \\
\text { insertions }\end{array}$ \\
\hline 16 & $36.94 \pm 24.12$ & $99.37 \pm 24.56$ \\
\hline 1 & $377.36 \pm 36.88$ & $554.81 \pm 38.81$ \\
\hline
\end{tabular}

Data are presented as means $\pm \mathrm{SD}$.

els. However, it is important to note that the electrodeto-modiolar distance measurements in this study were all determined for an electrode that was designed to be positioned at the lateral wall. Furthermore, the studies in which perimodiolar arrays were compared with straight (lateral) arrays did not demonstrate an unequivocal correlation between the electrode-to-modiolar distance and the levels. Some studies showed that electrodes positioned perimodiolarly were associated with lower levels [Saunders et al., 2002], whereas others did not find such an effect for the distance to the modiolus [Huang et al., 2006; Long et al., 2014; Marrinan et al., 2004; van der Beek et al., 2005]. Additionally, at most a trend but no significant correlation was found between the distance to the modiolus and word score in our study. This lack of correlation might have been influenced by the fact that all our data were obtained with lateral wall electrodes, as other studies including both lateral wall and perimodiolar electrodes mentioned a significant correlation between the intracochlear positioner and word scores [Holden et al., 2013; van der Beek et al., 2005].

Gordin et al. [2010] showed that lateral packing of the cochleostomy decreased the basal ECAP thresholds and increased the midarray thresholds. The packing most likely decreased the basal distance to the modiolus and increased this distance for the midarray. This hypothesis is consistent with the distances to the modiolus that were observed in our study population (fig. 2), in which an extended round-window approach with lateral packing was applied. Nevertheless, despite the smaller distance from the basal contacts to the modiolus (fig. 2; table 4), the Tlevels increased at the basal end of the cochlea, and an increased electrode-to-modiolar distance was ruled out as the cause of this increase toward the base.
A T-level profile with increased levels toward the basal end (fig. 3) has been frequently reported in the literature [Baudhuin et al., 2012; Botros and Psarros, 2010; Cafarelli et al., 2005; D’Elia et al., 2012; Lai et al., 2009; Miller et al., 2008; Polak et al., 2005; Smoorenburg et al., 2002; Thai-Van et al., 2001; van der Beek et al., 2015; Vargas et al., 2013]. However, there is no clear explanation for this phenomenon. Elucidating the causes of this phenomenon could provide insights for improving fitting and future electrode development. Although a clear increase in the T-levels toward the basal end was observed in various subgroups (fig. 5a), not all of the subjects showed such an increase. The variation among the subjects could be caused by different factors. However, $20 \%$ of the intrapatient variation was related to the basal increase in the Tlevels, suggesting that there is a common cause for this occurrence (fig. 3b, quadratic fit, $\mathrm{r}=0.2$ ).

An increased T-level suggests a suboptimal neuronelectrode interface. If the basal increase is caused by central pathways, no possible improvements at this particular site can be expected in the near future; this would also be the case if neural degeneration is the cause of the increase. If other peripheral aspects cause the deterioration of the neuron-electrode interface and cause differences along the array, determining their contribution might lead to improvements in future electrode designs.

Based mainly on data obtained using experimental animals, Shibata et al. [2011] concluded that deafness generally causes neural degeneration that leads to a progressively smaller number of SGCs. However, Rask-Andersen et al. [2010] showed that even with degeneration of the organ of Corti, the SGCs were preserved. In our population, neither a longer duration of deafness nor an increased age at implantation affected the absolute levels or their profile along the array (fig. 7). Because SGCs can survive even after a long duration of deafness [Rask-Andersen et al., 2010] and the duration of deafness had no clear effect on the stimulation levels (fig. 7), the progressive degeneration of the neural elements (starting in those involved with the high frequencies) appears not to be the cause of the wide variation or the basal increase in the levels. Other factors (e.g. etiology) are likely to affect neural excitability and therefore the stimulation levels. However, although the T-levels of the patients varied greatly, the level profiles did not depend on the T-level [see also van der Beek et al., 2015], and all of the subgroups consistently showed a basal increase in the T-levels, as shown in figure 5 . The widely varying overall levels are generally thought to be correlated with an etiology-of-deafnessbased factor or another patient-specific factor, making it van der Beek/Briaire/van der Marel/ Verbist/Frijns 
less likely that the consistent, level-independent basal increase is associated with the same factor. In contrast, Propst et al. [2006] showed that patients who presumably had experienced neural degeneration that was equally distributed along the cochlea (GJB2 patients) had the same ECAP thresholds along the array, whereas the nonGJB2 patients had different thresholds along the array. Unfortunately, no direct connection between the data from Propst et al. [2006] and neural degeneration can be made because the authors did not conduct histological evaluations.

Another possible explanation for the basal increase could be the growth of fibrous tissue around the array. Indeed, tissue growth was mostly observed basally [Adunka et al., 2004; Fayad et al., 2009; Li et al., 2007]. Further, Kawano et al. [1998] found a correlation between new tissue formation and overall stimulation levels; this study, however, reported on only 5 subjects and did not show the varying effects of tissue formation on the levels along the array. Furthermore, figure 8 shows that the increase in the basal levels was the same at the initial fitting as at the 1-year follow-up. Therefore, if tissue formation was the cause of the basal increase, the effects would have to have occurred within the first 4 weeks following implantation (prior to the first fitting) and would not change in the year afterwards.

Because the basal increase in the stimulus levels was quite consistent among the different subgroups with different overall stimulation levels and speech perception scores, this phenomenon is likely to be the result of independent factors that cause differences in the overall levels. For example, basal trauma caused by drilling an extended round window or a cochleostomy is an overall level-independent factor [Adunka et al., 2004].

Based on the collected data and the analysis described above, we are inclined to conclude that the basal increase in the T-level is an inherent property of electrical stimulation in the human scala tympani. Therefore, the basal increase in the T-level should be caused by anatomical factors that are present in most patients. The thicker modiolar wall at the basal cochlear end [Shepherd and Colreavy, 2004] or the size of the basal scala [Rebscher et al., 2008] could be potential causes. The size of the basal cochlea could cause electrodes to be positioned on the floor of the basal turn, resulting in electrodes that are relatively far from the osseous spiral lamina, which would increase the thresholds, particularly in the presence of the peripheral processes of the SGCs [Shepherd et al., 1993].

CT data demonstrating the intracochlear position of the electrodes can facilitate fitting patients whose depth of insertion is well outside the normal range. For the average patient, CT data will be of limited help, particularly because the distance between the contacts and the modiolus does not have a significant effect on the stimulation levels. Most likely, a combination of factors causes the differences in stimulation levels along the array. Further research should be performed to elucidate the individual contributions of those factors. This knowledge might help to improve electrode design. At present, patients can be fitted with sufficient emphasis on the basal part of the cochlea, using published data as references. Finally, based on this data, different fitting strategies should be examined to assess the effect of those strategies on the daily performance of the implant.

\section{References}

-Adunka O, Gstoettner W, Hambek M, Unkelbach $\mathrm{MH}$, Radeloff A, Kiefer J: Preservation of basal inner ear structures in cochlear implantation. ORL J Otorhinolaryngol Relat Spec 2004;66:306-312.

Baudhuin J, Cadieux J, Firszt JB, Reeder RM, Maxson JL: Optimization of programming parameters in children with the Advanced $\mathrm{Bi}$ onics cochlear implant. J Am Acad Audiol 2012;23:302-312

-Bierer JA, Faulkner KF: Identifying cochlear implant channels with poor electrode-neuron interface: partial tripolar, single-channel thresholds and psychophysical tuning curves. Ear Hear 2010;31:247-258.
Blamey P, Artieres F, Baskent D, Bergeron F, Beynon A, Burke E, Dillier N, Dowell R, Fraysse B, Gallego S, Govaerts PJ, Green K, Huber AM, Kleine-Punte A, Maat B, Marx M, Mawman D, Mosnier I, O'Connor AF, O'Leary S, Rousset A, Schauwers K, Skarzynski H, Skarzynski PH, Sterkers O, Terranti A, Truy E, Van de Heyning P, Venail F, Vincent C, Lazard DS: Factors affecting auditory performance of postlinguistically deaf adults using cochlear implants: an update with $2,251 \mathrm{pa}$ tients. Audiol Neurootol 2013;18:36-47.

- Blamey PJ, Pyman BC, Gordon M, Clark GM, Brown AM, Dowell RC, Hollow RD: Factors predicting postoperative sentence scores in postlinguistically deaf adult cochlear implant patients. Ann Otol Rhinol Laryngol 1992;101: 342-348.
Intracochlear Position of Cochlear Implants: CT Scanning vs. Fitting Levels
Audiol Neurotol 2016;21:54-67 DOI: $10.1159 / 000442513$ Dutch CVC syllables and sentences for listeners with normal hearing and with three types of hearing impairment. Audiology 1995;34: 260-284.

Botros A, Psarros C: Neural response telemetry reconsidered. I. The relevance of ECAP threshold profiles and scaled profiles to cochlear implant fitting. Ear Hear 2010;31:367379.

Briaire JJ, Frijns JHM: The relative value of predictive factors of cochlear implant performance depends on follow-up time; in Briaire JJ (ed): Cochlear Implants from Model to Patients. Leiden, Leiden University, 2008, pp 161-162. 
-Cafarelli DD, Dillier N, Lai WK, von WE, van DB, Akdas F, Aksit M, Batman C, Beynon A, Burdo S, Chanal JM, Collet L, Conway M, Coudert C, Craddock L, Cullington H, Deggouj N, Fraysse B, Grabel S, Kiefer J, Kiss JG, Lenarz T, Mair A, Maune S, Muller-Deile J, Piron JP, Razza S, Tasche C, Thai-Van H, Toth F, Truy E, Uziel A, Smoorenburg GF: Normative findings of electrically evoked compound action potential measurements using the neural response telemetry of the Nucleus CI24M cochlear implant system. Audiol Neurootol 2005; 10:105-116.

D'Elia A, Bartoli R, Giagnotti F, Quaranta N: The role of hearing preservation on electrical thresholds and speech performances in cochlear implantation. Otol Neurotol 2012;33: 343-347.

-Eisen MD, Franck KH: Electrode interaction in pediatric cochlear implant subjects. J Assoc Res Otolaryngol 2005;6:160-170.

- Fayad JN, Makarem AO, Linthicum FH Jr: Histopathologic assessment of fibrosis and new bone formation in implanted human temporal bones using 3D reconstruction. Otolaryngol Head Neck Surg 2009;141:247-252.

-Finley CC, Holden TA, Holden LK, Whiting BR, Chole RA, Neely GJ, Hullar TE, Skinner MW: Role of electrode placement as a contributor to variability in cochlear implant outcomes. Otol Neurotol 2008;29:920-928.

-Frijns JH, Briaire JJ, de Laat JA, Grote JJ: Initial evaluation of the Clarion CII cochlear implant: speech perception and neural response imaging. Ear Hear 2002;23:184-197.

Frijns JH, Klop WM, Bonnet RM, Briaire JJ: Optimizing the number of electrodes with highrate stimulation of the Clarion CII cochlear implant. Acta Otolaryngol 2003;123:138-142.

-Gordin A, Papsin B, Gordon K: Packing of the cochleostomy site affects auditory nerve response thresholds in precurved off-stylet cochlear implants. Otol Neurotol 2010;31:204209.

Holden LK, Finley CC, Firszt JB, Holden TA, Brenner C, Potts LG, Gotter BD, Vanderhoof SS, Mispagel K, Heydebrand G, Skinner MW: Factors affecting open-set word recognition in adults with cochlear implants. Ear Hear 2013;34:342-360.

Huang TC, Reitzen SD, Marrinan MS, Waltzman SB, Roland JT: Modiolar coiling, electrical thresholds, and speech perception after cochlear implantation using the Nucleus Contour advance electrode with the advance off stylet technique. Otol Neurotol 2006;27:159-166.

-Kawano A, Seldon HL, Clark GM, Ramsden RT, Raine $\mathrm{CH}$ : Intracochlear factors contributing to psychophysical percepts following cochlear implantation. Acta Otolaryngol 1998;118: 313-326.

Lai WK, Dillier N, Weber BP, Lenarz T, Battmer R, Gantz B, Brown C, Cohen N, Waltzman S, Skinner M, Holden L, Cowan R, Busby P, Killian M: TNRT profiles with the Nucleus Research Platform 8 system. Int J Audiol 2009;48:645-654.
Li PM, Somdas MA, Eddington DK, Nadol JB Jr: Analysis of intracochlear new bone and fibrous tissue formation in human subjects with cochlear implants. Ann Otol Rhinol Laryngol 2007;116:731-738.

Long CJ, Holden TA, McClelland GH, Parkinson WS, Shelton C, Kelsall DC, Smith ZM: Examining the electro-neural interface of cochlear implant users using psychophysics, CT scans, and speech understanding. J Assoc Res Otolaryngol 2014;15:293-304.

- Marrinan MS, Roland JT Jr, Reitzen SD, Waltzman SB, Cohen LT, Cohen NL: Degree of modiolar coiling, electrical thresholds, and speech perception after cochlear implantation. Otol Neurotol 2004;25:290-294.

Micco AG, Richter CP: Tissue resistivities determine the current flow in the cochlea. Curr Opin Otolaryngol Head Neck Surg 2006;14: 352-355.

Miller CA, Brown CJ, Abbas PJ, Chi SL: The clinical application of potentials evoked from the peripheral auditory system. Hear Res 2008; 242:184-197.

Nadol JB Jr: Patterns of neural degeneration in the human cochlea and auditory nerve: implications for cochlear implantation. Otolaryngol Head Neck Surg 1997;117:220-228.

-Nelson DA, Kreft HA, Anderson ES, Donaldson GS: Spatial tuning curves from apical, middle, and basal electrodes in cochlear implant users. J Acoust Soc Am 2011;129:3916-3933.

Noble JH, Labadie RF, Gifford RH, Dawant BM: Image-guidance enables new methods for customizing cochlear implant stimulation strategies. IEEE Trans Neural Syst Rehabil Eng 2013;21:820-829.

O'Malley JT, Burgess BJ, Zhu MY, Curtin HD, Nadol JB Jr: Correlation between histologic and radiographic reconstruction of intracochlear electrode position in human temporal bones. Audiol Neurootol 2014;19:184-192.

Pfingst BE, Xu L: Psychophysical metrics and speech recognition in cochlear implant users. Audiol Neurootol 2005;10:331-341.

Pfingst BE, Xu L, Thompson CS: Across-site threshold variation in cochlear implants: relation to speech recognition. Audiol Neurootol 2004;9:341-352.

Polak M, Hodges A, Balkany T: ECAP, ESR and subjective levels for two different Nucleus 24 electrode arrays. Otol Neurotol 2005;26:639645.

Polak M, Hodges AV, King JE, Balkany TJ: Further prospective findings with compound action potentials from Nucleus 24 cochlear implants. Hear Res 2004;188:104-116.

Propst EJ, Papsin BC, Stockley TL, Harrison RV, Gordon KA: Auditory responses in cochlear implant users with and without GJB2 deafness. Laryngoscope 2006;116:317-327.

Rask-Andersen H, Liu W, Linthicum F: Ganglion cell and 'dendrite' populations in electric acoustic stimulation ears. Adv Otorhinolaryngol 2010;67:14-27.
Rebscher SJ, Hetherington A, Bonham B, Wardrop P, Whinney D, Leake PA: Considerations for design of future cochlear implant electrode arrays: electrode array stiffness, size, and depth of insertion. J Rehabil Res Dev 2008;45:731-747.

Ruivo J, Mermuys K, Bacher K, Kuhweide R, Offeciers E, Casselman JW: Cone beam computed tomography, a low-dose imaging technique in the postoperative assessment of cochlear implantation. Otol Neurotol 2009;30: 299-303.

- Saunders E, Cohen L, Aschendorff A, Shapiro W, Knight M, Stecker M, Richter B, Waltzman S, Tykocinski M, Roland T, Laszig R, Cowan R: Threshold, comfortable level and impedance changes as a function of electrode-modiolar distance. Ear Hear 2002;23:28S-40S.

- Shepherd RK, Colreavy MP: Surface microstructure of the perilymphatic space: implications for cochlear implants and cell- or drug-based therapies. Arch Otolaryngol Head Neck Surg 2004;130:518-523.

-Shepherd RK, Hatsushika S, Clark GM: Electrical stimulation of the auditory nerve: the effect of electrode position on neural excitation. Hear Res 1993;66:108-120.

- Shibata SB, Budenz CL, Bowling SA, Pfingst BE, Raphael Y: Nerve maintenance and regeneration in the damaged cochlea. Hear Res 2011; 281:56-64.

Smoorenburg GF: Cochlear Implant Ear Marks. Utrecht, University Medical Center Utrecht, 2007, pp 15-34.

Smoorenburg GF, Willeboer C, van Dijk JE: Speech perception in Nucleus CI24M cochlear implant users with processor settings based on electrically evoked compound action potential thresholds. Audiol Neurootol 2002;7: 335-347.

Thai-Van H, Chanal JM, Coudert C, Veuillet E, Truy E, Collet L: Relationship between NRT measurements and behavioral levels in children with the Nucleus 24 cochlear implant may change over time: preliminary report. Int J Pediatr Otorhinolaryngol 2001;58:153162.

- van der Beek FB, Boermans PP, Verbist BM, Briaire JJ, Frijns JH: Clinical evaluation of the Clarion CII HiFocus 1 with and without positioner. Ear Hear 2005;26:577-592.

-van der Beek FB, Briaire JJ, Frijns JH: Effects of parameter manipulations on spread of excitation measured with electrically evoked compound action potentials. Int J Audiol 2012;51: 465-474.

van der Beek FB, Briaire JJ, Frijns JH: Populationbased prediction of fitting levels for individual cochlear implant recipients. Audiol Neurootol 2015;20:1-16.

van Wermeskerken GK, van Olphen AF, Graamans K: Imaging of electrode position in relation to electrode functioning after cochlear implantation. Eur Arch Otorhinolaryngol 2009;266:1527-1531. 
Vargas JL, Sainz M, Roldan C, Alvarez I, de la Torre A: Analysis of electrical thresholds and maximum comfortable levels in cochlear implant patients. Auris Nasus Larynx 2013;40: 260-265.

Verbist BM, Frijns JH, Geleijns J, van Buchem MA: Multisection CT as a valuable tool in the postoperative assessment of cochlear implant patients. AJNR Am J Neuroradiol 2005;26: 424-429.

-Verbist BM, Joemai RM, Briaire JJ, Teeuwisse WM, Veldkamp WJ, Frijns JH: Cochlear coordinates in regard to cochlear implantation: a clinically individually applicable 3 dimensional CT-based method. Otol Neurotol 2010a;31:738-744.
Verbist BM, Joemai RM, Teeuwisse WM, Veldkamp WJ, Geleijns J, Frijns JH: Evaluation of 4 multisection CT systems in postoperative imaging of a cochlear implant: a human cadaver and phantom study. AJNR Am J Neuroradiol 2008;29:1382-1388.

Verbist BM, Skinner MW, Cohen LT, Leake PA, James C, Boex C, Holden TA, Finley CC, Roland PS, Roland JT Jr, Haller M, Patrick JF, Jolly CN, Faltys MA, Briaire JJ, Frijns JH: Consensus panel on a cochlear coordinate system applicable in histologic, physiologic, and radiologic studies of the human cochlea. Otol Neurotol 2010b;31:722-730.
Wesarg T, Battmer RD, Garrido LC, Dillier N, Garcia-Ibanez L, Hey M, Macias AR, Irujo AH, Morsnowski A, Offeciers EF, Zarowski A, Pesch J, Rypkema G, Smoorenburg GF: Effect of changing pulse rate on profile parameters of perceptual thresholds and loudness comfort levels and relation to ECAP thresholds in recipients of the Nucleus CI24RE device. Int J Audiol 2010;49:775787.

Wilson BS, Finley CC, Lawson DT, Wolford RD, Eddington DK, Rabinowitz WM: Better speech recognition with cochlear implants. Nature 1991;352:236-238. 